\title{
ADAPTIVE AND FUNGTIONAL POLYMERS, TEXTILES AND THEIR APPLICATIONS
}


This page is intentionally left blank 


\title{
ADAPTIVE AND FUNGTIONAL POLYMERS, TEXTILES AND THEIR APPLICATIONS
}

\author{
Jinlian $\mathrm{Hu}$ \\ The Hong Kong Polytechnic University, Hong Kong
}


Published by

Imperial College Press

57 Shelton Street

Covent Garden

London WC2H 9HE

\section{Distributed by}

World Scientific Publishing Co. Pte. Ltd.

5 Toh Tuck Link, Singapore 596224

USA office: 27 Warren Street, Suite 401-402, Hackensack, NJ 07601

UK office: 57 Shelton Street, Covent Garden, London WC2H 9HE

\section{British Library Cataloguing-in-Publication Data}

A catalogue record for this book is available from the British Library.

\section{ADAPTIVE AND FUNCTIONAL POLYMERS, TEXTILES AND THEIR APPLICATIONS}

Copyright () 2011 by Imperial College Press

All rights reserved. This book, or parts thereof, may not be reproduced in any form or by any means, electronic or mechanical, including photocopying, recording or any information storage and retrieval system now known or to be invented, without written permission from the Publisher.

For photocopying of material in this volume, please pay a copying fee through the Copyright Clearance Center, Inc., 222 Rosewood Drive, Danvers, MA 01923, USA. In this case permission to photocopy is not required from the publisher.

ISBN-13 978-1-84816-475-8

ISBN-10 1-84816-475-0

Printed in Singapore. 


\section{Preface}

As smart materials, adaptive polymers can show sharp, controllable and predictable changes as responses to the external stimuli and have attracted more and more interests in their properties, structures, innovative design and applications. Many technological breakthroughs have been achieved during the past several decades. As the demands in new functions and enhanced performance of industrial and consumer products, some functional polymers have also been extensively explored and shown tremendous application potential.

In order to provide a resource for people in different professions in searching for knowledge and applications in adaptive and versatile functional polymers, this book has covered their latest developments as well as their applications in textiles, medical and cosmetics fields. The concepts and adaptive mechanisms are introduced. Their characteristics through different application fields have been presented. The applications of adaptive polymers to textiles have been highlighted. One of the unique features of this book is its interdisciplinary in nature.

In Chapter 1, basic concepts are suggested and definitions of adaptive polymers and textiles are reviewed. Following that, the characteristics, structures and potential applications of adaptive polymers are summarised. In Chapter 2, shape memory polymers according to their molecular structures, trigger patterns and applications are introduced based on literature review. One of the novel functional shape memory polymers with substrate bonded antibacterial activity is detailed and a new design of supramolecular shape memory polymers is discussed. Finally, shape memory fibers are compared with other existing manmade fibers to clarify the uniqueness of such smart textile materials. 
Adaptive polymeric gels are a class of smart materials and such hydrogels can respond to changes in different environment such as temperature and $\mathrm{pH}$. It is an exciting feature of intelligent materials. Due to their hydrophilic and biocompatible nature, most of them are used as biomaterials in medical and cosmetics areas. In Chapter 3, we have detailed this type of adaptive polymeric materials.

Adaptive polymeric particles can be made in different forms. One of the major features, which affect their properties and applications, is their particle size. The structure of core-shell and microencapsulation has made the adaptive polymeric particles incomparable position. The new developments of synthesis and characterization techniques of adaptive polymers have provided various ways in textiles and cosmetics. Therefore, Chapter 4 has focused on the discussions of polymeric particles and their applications.

Some groundbreaking contributions to the advancement of adaptive polymers, particularly in relation to textiles, have been made in the Hong Kong Polytechnic University. Towards the goal, fundamental adaptive textiles researches were carried out and some related models have been developed. The novel applications are the issues of Chapter 5 in adaptive textiles.

Many advances of adaptive composites with adaptive polymers are made in the past several decades. As a newborn, adaptive polymeric composite has brought new applications in modern academics and industries. The research into the interrelationship of processing, structure, property and performance is now the essence of adaptive polymeric composites. We have detailed the progress in this area in Chapter 6.

In Chapter 7, fabrication of nanofibres and nanofilms by electrospinning and self-assembly methods are introduced. At the same time, the principles and parameters of electrospinning and self-assembly are discussed. The morphologies and structures of nanofibres and nanofibrous nonwovens are described briefly. A comprehensive understanding of adaptive nanofibres and nanofilms can be obtained in this chapter.

Many original developments of cosmetics are founded on the combination of materials, biomedical sciences and technologies. Adaptive polymeric materials would greatly promote their innovation of 
cosmetics applications. The research efforts in adaptive polymers can improve the quality of life for beauty in a substantial trend. In our Chapter 8, we have detailed the above contents.

The technological advances of life sciences in the last decades significantly accelerated the medical research and developments. New horizons for the applications of adaptive and functional polymers in medical kingdom have been opened and more and more methods are developed to meet the practical requirements. Modern adaptive polymers and textiles are tailor-made to meet a wide variety of innovative applications including the biomimic and intelligent textiles. The medical applications of adaptive and functional polymers have been discussed and an outlook into the potential future developments is provided in Chapter 9.

The subsequent contents of the book focus on the four types of versatile functional polymers: dendrimers, hyperbranched polymers, chitosan and cyclodextrin. The major advancements in relative fields are detailed. Various application examples are presented. Their characteristics are highlighted and challenges to be addressed in the near future are pointed out.

The following are the major features of this book:

1. Focused on adaptive polymers. There are many smart and functional materials and adaptive systems, but we have mainly focused on adaptive polymers with some functional ones, which we have experience with and which we believe are important for new generations of materials and products.

2. Integrative in nature. The book has covered molecular design, synthesis, structure and properties, characterisation method and applications of adaptive polymers.

3. Cross-disciplinary teams' research work. Since the book needs to cover wide spectrum of contents from a vertical and horizontal points of view cross-disciplinary knowledge, understanding is very important. This is reflected in the book and is from our research work and team in the Shape Memory Textile Center in the Hong Kong Polytechnic University where we have more than 20 people in 
the group every year with research expertise in polymer synthesis, physics, engineering and applications, biological and medical and cosmetics, textiles and apparel processing and evaluation.

4. Application oriented. Over the past ten years, we have been looking for materials for textile applications and once we started to research into Shape Memory Polymers, we have been working on different applications of adaptive polymers. Every week we have at least one meeting to review, brainstorm, design, discuss and develop different applications of adaptive materials and products. This application oriented research can benefit the readers with a good understanding of the potentials of these adaptive polymers.

5. Extensive partnership with different organiszations, particularly companies. In the past ten years, we have been working with local and international companies (including market players P\&G, TAL, etc.) to develop new materials and products. These cover textile, apparel and intimate products, medical devices, cosmetics, etc. In addition, because of our pioneering work, companies visited us and we visited over 200 including market players such as BASF, Clariant, Smith and Nephew. This experience has given us a very unique opportunity to penetrate into the market and understand the needs of industries. This is a very important driving force for us to explore adaptive polymers day and night for many years and this partially reflected in the book.

6. Long term and pioneering research in adaptive polymers, particularly shape memory polymers.

With the above features and contents, we believe that this book will be a valuable reference to many people in different professions and at different levels/stages of their research careers in companies, universities and research institutes. 


\section{Contents}

Preface $\quad$ V

$\begin{array}{lc}\text { Acknowledgements } & \text { xxi }\end{array}$

Chapter 1 Introduction to Adaptive Polymers and Textiles 1

1.1 Concepts of adaptive polymers and textiles 2

1.1.1 Introduction to adaptive polymers 2

1.1.2 Introduction to adaptive textiles $\quad 5$

$\begin{array}{ll}1.2 \text { Adaptive polymers } & 6\end{array}$

1.2.1 Shape memory polymers $\quad 8$

1.2.2 Adaptive polymeric hydrogels 9

$\begin{array}{ll}1.2 .3 \text { Adaptive polymeric particles } & 10\end{array}$

$\begin{array}{ll}1.3 \text { Adaptive textiles } & 12\end{array}$

$\begin{array}{ll}\text { 1.3.1 Adaptive nanofibres and nanofilms } & 13\end{array}$

$\begin{array}{ll}\text { 1.3.2 Shape memory fibres and fabrics } & 15\end{array}$

$\begin{array}{ll}1.4 \text { Framework of the book } & 16\end{array}$

$\begin{array}{ll}1.5 \text { Future aspects and summary } & 18\end{array}$

$\begin{array}{ll}\text { References } & 19\end{array}$

$\begin{array}{lll}\text { Chapter } 2 \text { Shape Memory Polymers } & 24\end{array}$

2.1 Introduction 25

2.2 Principles of shape memory function in SMPs 25

$\begin{array}{ll}2.3 \text { Classification of SMPs } & 27\end{array}$

2.3.1 Molecular structures of SMPs $\quad 27$

2.3.1.1 Covalent bond between switches and net-points 27

2.3.1.2 Non-covalent bond between switches and net-points 29

2.3.2 Trigger patterns of SMPs 30 
2.3.2.1 Direct thermal senstitive shape memory effect $\quad 30$

2.3.2.2 Indirect thermal sensitive shape memory effect 31

2.3.2.3 Other external stimulus 33

2.3.2.3.1 Light as external stimulus 33

2.3.2.3.2 Multi-external stimulus in hydrogels $\quad 34$

2.3.3 Applications of SMPs $\quad 35$

2.3.3.1 SMPs used for bio-medical areas $\quad 36$

2.3.3.1.1 Fixity and orthodontic application $\quad 36$

2.3.3.1.2 Smart implant materials $\quad 37$

2.3.3.1.3 Micro-acturator and others in biomedical 38 areas

2.3.3.2 SMPs applied to textiles 38

2.3.3.3 Usage in thermal recording, sensors, actuators and 39 others

2.4 SMPs with substrate bonded antibacterial activity 41

2.4.1 Molecular structure of SMP with antibacterial activity $\quad 42$

2.4.2 Characterisation of substrate bonded antibacterial activity $\quad 44$

2.4.3 Shape memory function $\quad 47$

2.5 Supramolecular SMPs 49

2.5.1 Molecular design of supramolecular SMPs 49

2.5.2 Characterisation of supramolecular SMPs with AFM, DMA 51

2.5.3 Shape memory function of supramolecular SMP 53

$\begin{array}{ll}2.6 \text { Shape memory fibres } & 57\end{array}$

$\begin{array}{ll}\text { 2.6.1 One way shape memory fibre } & 57\end{array}$

2.6.2 Two way shape memory fibres $\quad 60$

$\begin{array}{ll}\text { References } & 61\end{array}$

Chapter 3 Adaptive Polymeric Gels and Applications 72

$\begin{array}{ll}3.1 \text { Introduction } & 73\end{array}$

$\begin{array}{ll}3.1 .1 \text { Introduction of gels } & 73\end{array}$

3.1.2 Introduction of polymeric hydrogels $\quad 74$

$\begin{array}{ll}3.2 \text { Classification and molecular structure of polymeric gels } & 77\end{array}$

$\begin{array}{ll}\text { 3.2.1 Classification of polymeric gels } & 77\end{array}$

$\begin{array}{ll}\text { 3.2.2 Gels formation by intermolecular bonding } & 79\end{array}$

3.2.3 Gels design criteria for hydrogels $\quad 80$

3.2.4 Theory and principles of gelation $\quad 81$

3.3 Synthesis of adaptive polymeric gels $\quad 82$

3.3.1 Fundamentals of gelation $\quad 82$ 
3.3.2 Swelling theory of hydrogels

3.3.3 Adaptive sensitive hydrogels $\quad 83$

3.3.4 Preparation of adaptive hydrogels $\quad 85$

3.3.4.1 Grafting methods onto cellulose based nonwovens $\quad 85$

3.3.4.2 Plasma treatment 86

3.3.4.3 $\gamma$-ray pre-irradiation $\quad 86$

$\begin{array}{ll}\text { 3.3.4.4 UV-irradiation } & 87\end{array}$

3.3.4.5 Free radical polymerisation $\quad 87$

$\begin{array}{ll}3.4 \text { Properties and applications of adaptive polymeric gels } & 90\end{array}$

3.4.1 Volume phase transition of polymeric gels $\quad 90$

3.4.2 Properties of adaptive hydrogels $\quad 92$

3.4.3 Applications of hydrogels 96

3.4.4 Applications of adaptive hydrogels $\quad 97$

$\begin{array}{ll}3.5 \text { Summary } & 99\end{array}$

References $\quad 100$

Chapter 4 Adaptive Polymeric Particles and Applications 107

4.1 Introduction of polymeric particles 108

4.2 Classification of adaptive polymeric particles $\quad 109$

4.3 Properties of adaptive polymeric particles 111

4.3.1 Surface properties of polymeric particles 112

$\begin{array}{ll}\text { 4.3.2 Size of polymeric particles } & 113\end{array}$

4.3.3 Shape of polymeric particles $\quad 114$

4.3.4 Modification of polymeric particles $\quad 116$

4.4 Manufacturing of polymeric particles 116

$\begin{array}{ll}\text { 4.4.1 Aggregation theory } & 117\end{array}$

4.4.2 Manufacturing polymeric particles 118

$\begin{array}{ll}\text { 4.4.2.1 Sol-gel process } & 120\end{array}$

4.4.2.2 Surface modification of particles 120

4.4.2.3 Fabrication of core-shell structure polymeric $\quad 121$ particles

4.4.2.4 Micro-encapsulation technology 121

4.5 Applications of adaptive particles 124

4.5.1 Application to textiles and fibres $\quad 125$

4.5.1.1 Nanoparticple modification on textiles $\quad 125$

4.5.1.2 Self cleaning modification on textiles $\quad 126$

4.5.1.3 Shape memory finishing on textiles 126

4.5.1.4 Micro-encapsulation on textiles 128 
4.5.1.5 Phase change material particles

4.5.2 Applications in medicine

4.5.2.1 Biodegradable polymer micro-hydrogels

4.5.2.2 Nanoparticles in gene therapy

4.5.2.3 Particles in drug delivery

4.5.3 Application to cosmetics

4.5.3.1 Particles on makeup cosmetics

4.5.3.2 Particles on skin cosmetics

4.6 Summary

References

\section{Chapter 5 Adaptive Textiles Using Adaptive Polymers}

5.1 Adaptive textiles for thermoregulation

5.1.1 Types of phase change materials

5.1.2 Incorporation method of PCMs in textiles $\quad 144$

5.1.2.1 Fibre technology 144

5.1.2.2 Coating method 146

5.1.2.3 Laminating method 146

$\begin{array}{ll}\text { 5.1.3 Applications in adaptive garments } & 147\end{array}$

5.2 Shape memory polymeric textiles 148

5.2.1 Shape memory polymeric fibres 149

5.2.2 Shape memory function from fibre to fabrics $\quad 152$

5.2.2.1 Self-adaptability of shape memory fabrics $\quad 152$

5.2.2.2 Self-repairability of shape memory fabrics $\quad 152$

5.2.3 Shape memory garments $\quad 155$

5.2.4 Shape memory finishing fabrics and garments $\quad 157$

5.3 Adaptive chameleon textiles 158

5.3.1 Types of chameleon materials for adaptive textiles $\quad 159$

5.3.2 Application methods of chameleon materials in textiles $\quad 161$

5.4 Luminescent adaptive textiles 163

5.4.1 Introduction of luminescent materials 163

5.4.2 Applications of luminescent in adaptive textiles 164

5.5 Conductive polymer textile $\quad 165$

5.5.1 Conducting polymer fibres, fabrics and sensors $\quad 166$

5.5.2 Applications in textiles 168

5.6 Other functional textiles 169

5.6.1 Nano-technology applications in textiles 169

$\begin{array}{ll}\text { 5.6.1.1 Water repellence } & 169\end{array}$ 
5.6.1.2 Antibacterial properties

5.6.1.3 Self cleaning $\quad 170$

5.6.1.4 UV protection $\quad 171$

5.6.1.5 Antistatic properties 172

5.6.2 Intelligent impact protection textiles 172

$\begin{array}{ll}5.7 \text { Perspective } & 173\end{array}$

References 173

Chapter 6 Adaptive Polymeric Composites and Applications 180

6.1 Introduction 181

6.2 Thermal adaptive polymeric composites 181

6.2.1 Introduction of thermal adaptive polymeric composites $\quad 181$

6.2.2 Thermal adaptive SMP reinforcement 182

6.2.3 Polymer/polymer blending with thermal adaptive effect $\quad 183$

6.2.4 SMP/thermoexpanded graphite (TEG) 184

6.2.5 Thermal expansion of SMP composites 185

6.2.6 Thermal conductivity of SMP composites 185

6.2.7 Micro-mechanics of SMP composites 186

6.2.8 SMP composites with special functions 186

6.2.9 Development trends of thermal adaptive SMP composites 187

6.2.9.1 SMP composites based on non-thermal phase $\quad 188$ transition

6.2.9.2 Two-way SMP composites

6.3 Electro adaptive polymeric composites 189

6.3.1 Introduction of electro adaptive polymeric composites 189

6.3.2 Electrostrictive graft elastomers 190

6.3.3 Electrostrictive cellulose paper 191

6.3.4 Electro-viscoelastic elastomers 192

6.3.5 Ferroelectric electro adaptive polymers 192

6.3.6 Dielectric electro adaptive polymers 193

6.3.7 All-organic electro adaptive polymers 193

6.3.8 Electro adaptive liquid crystal elastomers 194

6.3.9 Electro adaptive conductive polymers 194

6.3.10 Electro adaptive composites from conductive thermal 195 adaptive SMPs

6.3.11 Electro adaptive ionomeric polymer-metal composites

6.3.12 Electro adaptive ionic polymer gels 196

6.3.13 Electro adaptive carbon nanotubes 197 
6.4 Light adaptive polymeric composites

6.4.1 Introduction of light adaptive polymeric composites

6.4.2 Photodeformability induced by photoisomerization

6.4.3 Photodeformablity induced by photoinduced ionic dissociation

6.4.4 Photodeformability induced by photoreactive molecules

6.4.5 Light adaptive composites from thermal adaptive SMPs

6.5 Magnetic adaptive polymeric composites

6.5.1 Introduction of magnetic adaptive polymeric composites

6.5.2 Magnetic adaptive elastomers

6.5.3 Magnetic adaptive gels

6.5.4 Magnetic adaptive SMPs

6.6 Moisture/water adaptive polymeric composites

6.6.1 Introduction of moisture/water adaptive polymeric composites

6.6.2 Moisture/water adaptive polymer with decreased switch temperature

6.6.3 Moisture/water adaptive polymer with hydrophilic segment

6.7 Applications to textiles

6.7.1 Thermal adaptive polymer composites for textile applications

6.7.2 Electro adaptive polymeric composites for textile applications

6.7.3 Light adaptive polymeric composites for textile applications

6.7.4 Magnetic adaptive composites for textile applications

6.7.5 Water/moisture adaptive polymeric composites for textile applications

6.8 Summary

References

Chapter 7 Adaptive Polymeric Nanofibre and Nanofilm 215

7.1 Introduction

7.2 Fabrication technologies 216

$\begin{array}{ll}7.2 .1 \text { Electrospinning } & 218\end{array}$

7.2.1.1 Definition of electrospinning 218

7.2.1.2 Principle of electrospinning 219 
7.2.1.3 Parameters of electrospinning

7.2.1.3.1 Solution concentrations/viscosity

7.2.1.3.2 Electrical voltage/applied voltage 221

7.2.1.3.3 Feeding rate 222

7.2.2 Self-assembly

7.2.2.1 Definition of self-assembly

223

7.2.2.2 Principle of self-assembly

7.2.2.2.1 Non-covalent interactions

7.2.2.2.2 Intermolecular packing

225

7.2.2.2.3 Biological self-assembly 225

7.2.2.2.4 Nanomotor 225

7.2.2.3 Advantages of self-assembly technology 226

7.3 Morphologies and structure

7.3.1 Structure of nanofibres

7.3.1.1 Huge surface area to volume ratio

7.3.1.2 Orientation structure

7.3.1.3 Surface structures of nanofibres 228

7.3.1.4 Core-shell nanofibres 229

7.3.2 Structure in nanofibrous nonwoven 229

$\begin{array}{ll}\text { 7.3.2.1 Fibre arrangement } & 229\end{array}$

7.3.2.2 Variation in diameter $\quad 230$

7.3.2.3 Pore structure 230

7.4 Development of adaptive nanofibres and nanofilms 231

7.4.1 Shape memory polymer nanofibres/non-woven 232

7.4.2 PH-responsive nanofibre/nanofilms 233

7.4.3 Adaptive phase change nanofibres 234

7.4.4 Nonlinear optical nanofibres $\quad 234$

7.4.5 Conducting nanofibres/nanofilms 236

7.4.6 Optoelectronic nanofilms 237

7.4.7 Bacterial cellulose nanofibres 238

$\begin{array}{ll}\text { 7.4.8 Adaptive composites } & 239\end{array}$

7.4.9 Others 240

7.5 Applications of nanofibres, nanofilms of adaptive polymers 241

$\begin{array}{ll}\text { 7.5.1 Protective clothing applications } & 241\end{array}$

7.5.2. Filtration applications 241

7.5.3 Biomedical application $\quad 242$

7.5.3.1 Delivery of drug and pharmaceutical composition 242

7.5.3.2 Tissue engineering 
7.5.3.3 Wound dressing

$\begin{array}{ll}\text { 7.5.4 Other functional application } & 244\end{array}$

References

Chapter 8 Cosmetics Applications of Adaptive and Functional 252 Polymers

8.1 Introduction

8.2 Definition, history and classification of cosmetics

8.2.1 Definition of cosmetics

8.2.2 Development history of cosmetics

8.2.2.1 Original cosmetics

8.2.2.2 Emulsion cosmetics

8.2.2.3 Functional cosmetics

8.2.2.4 Bionic cosmetics 255

8.2.3 Classification of cosmetics 256

8.2.4 Adaptive and functional polymers in cosmetics 257

8.2.4.1 Adaptive and functional polymers with unique 257 advantages

8.2.4.2 Increasing maturing technology in polymer industry

8.2.4.3 Consumer expectations

8.3 Cosmetic applications of adaptive and functional polymers 258

8.3.1 Hydrogels

8.3.2 Polysaccharides

8.3.3 Cyclodextrin

8.3.4 Shape memory polymers 268

$\begin{array}{ll}\text { 8.3.5 Nanopolymer particles } & 270\end{array}$

8.4 Glamourous prospects in the cosmetic field 274

$\begin{array}{ll}\text { 8.4.1 Multifunctional cosmetics } & 275\end{array}$

$\begin{array}{ll}\text { 8.4.2 Smart cosmetics } & 275\end{array}$

8.4.2.1 Adaptive hydrogel cosmetics 275

8.4.2.2 Shape memory cosmetics 276

8.4.3 Nanoparticle cosmetics 276

$\begin{array}{ll}8.5 \text { Summary } & 277\end{array}$

$\begin{array}{ll}\text { References } & 278\end{array}$

Chapter 9 Medical Applications of Adaptive Polymers 284

$\begin{array}{lll}9.1 \text { Introduction } & 285\end{array}$ 
9.2 Aims and requirements of medical adaptive polymers 285

9.2.1 Biocompatibility 286

9.2.2 Functionality 286

9.2.3 Nontoxicity 287

9.2.4 Mechanical properties $\quad 287$

9.2.5 Other properties 288

9.3 Adaptive polymeric materials for medical applications $\quad 288$

9.3.1 Adaptive polymeric materials for tissue engineering 288

9.3.1.1 Electroactive polymer for artificial muscles $\quad 288$

9.3.1.2 Biodegradable scalffold for tissue engineering 291

9.3.2 Adaptive polymeric materials for diagnosis and medical 294 treatments

9.3.2.1 Adaptive polymers in drug delivery 294

9.3.2.2 Smart polymer nanoparticles for diagnostics 298

9.3.2.3 Adaptive polymeric materials in biosensors 301

9.3.2.4 Adaptive polymeric materials for eye related $\quad 304$ materials

9.3.3 Adaptive polymeric materials for medical devices $\quad 307$

$\begin{array}{ll}9.4 \text { Summary } & 310\end{array}$

References 311

Chapter 10 Special Adaptive and Functional Polymers and Their 319 Applications

10.1 Structure, synthesis, properties and applications of dendrimer $\quad 319$ macromolecules

10.1.1 Introduction $\quad 319$

10.1.2 Synthesis of dendrimer macromolecules $\quad 320$

10.1.2.1 Divergent synthesis $\quad 320$

10.1.2.2 Convergent synthesis $\quad 322$

10.1.2.3 Other approaches with improved efficiency $\quad 323$

10.1.3 Properties and applications $\quad 325$

10.1.3.1 Medical applications $\quad 325$

10.1.3.2 Nanoscale catalyst $\quad 326$

10.1.3.3 Dendritic sensors $\quad 326$

10.1.3.4 Energy 'funnels' $\quad 327$

10.1.4 Applications in textiles $\quad 327$

10.1.4.1 Dye extraction $\quad 327$

10.1.4.2 Dyeing of PP fibres $\quad 328$ 
10.1.4.3 Dyeing of cotton

10.1.4.4 Multi-functional finishing of textiles $\quad 329$

10.1.5 Summary

10.2 Structure, synthesis, properties and applications of hyperbranched macromolecules

10.2.1 Introduction

10.2.2 Synthesis of hyperbranched macromolecules

10.2.2.1 Step-growth polycondensation of monomer $\mathrm{ABx}$

10.2.2.2 Self-condensing vinyl polymerisation

10.2.2.3 Ring-opening multibranching polymerisation of latent $\mathrm{ABx}$

10.2.2.4 Other strategies for the synthesis of hyperbranched 335 macromolecules

10.2.2.4.1 The $\mathrm{A}_{2}+\mathrm{B}_{2}$ route to hyperbranched macromolecules

10.2.2.4.2 Graft 'onto' and graft 'from' approaches

10.2.3 Properties and applications of hyperbranched macromolecules

10.2.3.1 Coating

10.2.3.2 Medicine

10.2.3.3 Polymer blending $\quad 337$

10.2.3.4 Toughening for epoxy-based composites $\quad 338$

10.2.3.5 Nonlinear optics (NLO) 338

10.2.4 Applications in textiles

10.2.4.1 Dyeing

10.2.4.2 Spinning $\quad 339$

10.2.5 Summary 339

10.3 Structure, properties of chitosan and its applications $\quad 340$

10.3.1 Definition and structure of chitosan $\quad 340$

10.3.2 Properties of chitosan 343

10.3.2.1 Degree of acetylation $\quad 345$

10.3.2.2 Solubility $\quad 345$

10.3.2.3 Crystallinity $\quad 345$

10.3.2.4 Swelling/deswelling (pH sensitivity) 346

10.3.2.5 Antibacterial activity 346

10.3.3 Applications of Chitosan 347

10.3.3.1 Chitosan based wound-dressing $\quad 349$ 
10.3.3.2 Chitosan modified PNIPAAm hydrogels

10.3.3.3 Chitosan antibacterial finishing on cotton

10.3.3.4 Chitosan durable press finishing on cotton $\quad 352$

10.3.3.5 Chitosan on dye applications

10.3.3.6 Chitosan finishing on silk 353

10.3.3.7 Chitosan fibres

10.3.4 Chitosan used in cosmetics 353

10.3.5 Summary $\quad 354$

10.4 Cyclodextrins $\quad 355$

10.4.1 Structure and properties of CDs 355

10.4.1.1 Structure of CDs 356

10.4.1.2 Physical and chemical properties of CDs $\quad 357$

10.4.1.3 Applications of CDs and CD complexes $\quad 359$

10.4.2 Applications of CDs to textiles $\quad 359$

10.4.2.1 Applications in textile dyeing $\quad 360$

10.4.2.2 Applications on textile finishing 361

10.4.2.3 Applications in textile functioning $\quad 362$

10.4.2.4 Applications in textile monitoring 363

10.4.3 Applications of CDs to skin/healthcare products 364

10.4.3.1 Applications in improving stability and $\quad 364$ bioavailability

10.4.3.2 Applications in change solubility $\quad 366$

10.4.3.3 Applications in control release 366

10.4.3.4 Applications in cahnge penetrability $\quad 367$

10.4.3.5 Applications in reduing inflammation and $\quad 368$ irritation

$\begin{array}{ll}\text { 10.4.4 Summary } & 369\end{array}$

$\begin{array}{ll}\text { References } & 369\end{array}$

$\begin{array}{ll}\text { Index } & 385\end{array}$ 
This page is intentionally left blank 


\section{Acknowledgements}

The contents of this book are based partially on the original and integrated work produced in my research group (Shape Memory Textile Center in the Hong Kong Polytechnic University) over the past ten years. A number of people have contributed to and assisted with the preparation of the manuscript and the author is especially grateful to the following: Dr Baohua Liu, who helped with format checking and editing of the manuscript throughout; Ms Susanna Li helped with organising and managing the files and correspondence. In general, I am deeply indebted to my research students, postdoctoral fellows and research assistants, who have made contributions to the major part of the contents and made the book possible.

Some original data and part of the contents are taken from the $\mathrm{PhD}$ theses written under my supervision by Dr Yong Zhu, Ms Haitao Zhuo, Dr Baohua Liu, Mr Qinghao Meng and Dr Xuemei Ding. In particular, Dr Yong Zhu has prepared Chapter 2 mainly based on his $\mathrm{PhD}$ thesis and some new developments. Dr Baohua Liu has provided chapters on Adaptive Polymeric Gels and Adaptive Polymeric Particles and Applications. Dr Jing Lu has integrated the contents of Chapter 5 on Adaptive Textiles made by adaptive polymers. Based on his $\mathrm{PhD}$ study, Mr Qinghao Meng edited the chapter on Adaptive Polymeric Composites. Adaptive Polymeric Nano-fiber and Nano-film is from Zhuo Hai Tao's $\mathrm{PhD}$ work. Cosmetics Applications of Adaptive and Functional Polymers was edited by Liu Ge, who was working with us and now moved to Australia for further studying. Medical Applications of Adaptive Polymers was co-edited by Zeng Wei and Wu Xinbo. The last chapter on Special Functional Polymers and Their Applications has combined 
the work of different people. The dendrimer and the hyperbranched polymers by Qinghao Meng, the Chitosan is partially from the work of Dr Baohua Liu and Cyclodextrin is provided by Wu Xingbo.

In addition, I would like to acknowledge the funding support of the Hong Kong Textile and Apparel industry as well as the Hong Kong Government through the Innovation and Technology Commission over the past years. From these industry-guided projects, development of shape memory garments/fabrics and development of shape memory fibers, we can realise the significance of shape memory polymers to the textile and apparel industry as well as to the academic world through the knowledge accumulated during these developments. 